\title{
The Role of Kiswahili in Furthering an Afrocentric Ethos
}

\author{
John Mũkonzi Mũsyoki ${ }^{1}$ \\ ${ }^{1}$ Department of Drama, University of Alberta, Edmonton, Canada \\ E-mail: musyoki@ualberta.ca
}

\begin{abstract}
This paper examines how Kiswahili as a major African language promotes African agency. The theoretical framework of the inquiry situates language at the centre of the attempt to promote an Afrocentric ethos within the context of decolonization while speaking to the dominant national identity in Africa. The arguments that shape and propel this paper invite us to consider how linguistic reclamation can help us subvert the dominant perception of the position of the African within the growing discourse of globality.
\end{abstract}

Keywords: Afrocentric Philosophy, African Agency, Postcolonial Identity, Decolonization

\section{Introduction}

This paper examines the role the Kiswahili language plays in the formation and propagation of African agency. The theoretical framework of the inquiry situates language at the centre of the attempt to promote an Afrocentric ethos within the context of decolonization while speaking to the dominant national identity in Africa. Using Molefi Kete Asante's notion of Afrocentric philosophy featured in $A n$ Afrocentric Manifesto, Ngugi wa Thiong'o's campaign for linguistic decolonization in Decolonizing the Mind and Ali Mazrui's probe into socio-political significance of Kiswahili language in Swahili State, we will delve into the possibilities Kiswahili offers as an organic African language in nurturing African agency.

The aspiration for an Afrocentric ethos aligns with the need to liberate African agency from Eurocentric linguistic modalities dominant sociologically, economically and politically. I argue that since Kiswahili developed as an African language, it reaches contextually as both a national language (in Kenya and Tanzania) and a regional language (East and Central Africa) while offering a strong possibility to counter colonial linguistic hegemony. The integrational character of Kiswahili offers a possibility of promoting an identity bigger and more relevant than the dominant national identity. However, this is not an endorsement of Kiswahili as the most important African language but an exemplification of how a language that is 'African' can foster a strong sense of African agency.

The main focus here is the idea of an African language. It is important above all to acknowledge that language nurtures an appreciative sensibility in which we see, accept, validate and appraise ourselves as key participants in our own reality. It is through language that we communicate within our communities, with our inner self and with others outside our communities and geographies. We rely on language to articulate ourselves through naming and description of things, ideas and our environs. Therefore, the crux of this paper invites us to consider how linguistic reclamation can help us subvert the dominant perception of the position of the African. We ought to ponder the quintessential role of African languages in furthering interventions which possess (promote) an Afrocentric ethos. This inquiry aims to challenge the current African identity and reality in light of the geo-political factors within the expanding discourse of globality.

\section{Excavating African Agency}

Asante advocates for a paradigm shift in how we think, perceive and talk about the African identity. Core to his proposition is the question of African agency. He posits that "Afrocentricity is a paradigmatic intellectual perspective that privileges African agency within the context of African history and culture transcontinentally and trans- 
generationally" (Manifesto 2). Asante broaches the broad spectrum upon which African agency falls. He instantiates that agency should mean the conception of

a human being who is capable of acting independently in his or her own best interest. [Thus] agency itself is the ability to provide the psychological and cultural resources necessary for the advancement of human freedom. In situations of 'un-freedom,' oppression, racial repression, the active idea within the concept of agent assumes the primary position. (Notes 2 )

Asante insists that it is crucial to make African agency "our object of inquiry [in order] to recognize the fragility of African agency in systems of social, economic, political and cultural hegemony" (Liberating 646). The underpinning argument here is, the impact of European colonialism should be acknowledged as an integral facet in the dialogue about the African experience. We have to question the locus and the basis of the ideas that have shaped the African experience. This attempt will help distinguish propagation of 're-colonization' of Africa from 'reclamation' of cultures that occupy the region that has come to be regarded as Africa.

Colonialism continues to shape the African experience and language occupies a central position in the questions that emerge. We cannot ignore the fact that national identity is the dominant form of identity in Africa today. The phenomenon of Africans being affiliated with a particular national identity prods us to investigate the ramifications that undermine the progression of indigenous cultures in the region that has come to be regarded as Africa in furtherance of an 'authentic' identity. Modernity plays a key role in the impediments that arise while trying to maintain a notion of African agency that is not shaped by European hegemony. Bill Ashcroft, Gareth Griffiths and Helen Tiffin point out that modernity is

fundamentally about conquest [and as] a discourse, [it] enabled the large-scale regulation of human identity both within Europe and its colonies. The emergence of modernity is conterminous with the emergence of Eurocentrism, and the European dominance of the world effected through imperial expansion. (161)

As Africans, we ought to be cognizant of the history and ideology that has impacted the modern-day conception of African identity. Prudence in the questions we raise ensures we are working towards a proper identification and definition of African agency; within the socio-cultural matrixes that continue to shape, produce, propel and propagate discussions on what we now regard as 'being an African subject.'
We somewhat have to excavate African agency from the unprivileged position in which it is situated. William Brown and Sophie Harman probe into the quintessential questions and considerations one should pose when examining the constrained nature of African agency. They ask:

[w] hat does African agency look like and how can we understand it? It is not an effort to deny the very obviously tight corners which constrain Africa's choices within the international system. These constraints, whether in the form of great powers, structures of economic disadvantage or disabling discourses, are real and persistent. (2)

It is then essential to acknowledge that understanding African agency entails a probe into the conditions that have shaped the conception of the African position as disadvantaged, unprivileged and subordinate.

\section{The Conception of Africa: Language, Ideology and History}

History

Asante reminds us that "[w]hen Europe colonized Africa, it also colonized the language used to speak about Africa" (Manifesto 28). If we are to establish a legitimate understanding of African agency, we thus have to liberate it from the colonial ideological entanglement. Ideological thought played a crucial part in the colonial domination of Africa. Ideology orients a person or a group of people and shapes the frame of thinking, action and perception. Some ideologies are imposed while others are adopted. Within the context of colonialism, most of the ideologies that shaped (and continue to shape) Africa were imposed. Imperialism, as a colonial ideology, played a big part in the inception and ongoing conception of the African identity. Mazrui historically elucidates that "Europe's greatest service to the people of Africa was not Western civilization which is under siege, or even Christianity, which is on the defensive. Europe's supreme gift was the gift of African identity" (Thought 284). Mazrui instantiates that the scramble and partition of Africa led to the "invention of Africa" (Thought 284). For a more precise analysis of the African identity, we should examine the political and cultural effect of the contact (or contract) between the African people and the other cultures through history. The questions emanating from the examination of the history of culture, politics, ideology and identity within the context of inter/intra-communal contact will bring us closer to understanding the conception of the African consciousness.

\section{African Consciousness}


Before the coming of Europeans, Arabs had already established a relationship with Africans mostly through trade and the spread of Islam. Mazrui identifies that in comparison, "Islam and the Arabs awakened Africa's Black consciousness, but a continental identity was still dormant" (Thought 284). It is the European colonialism that led to the ideation of the Africanization. The European

conceptualization of the African status was based on pigmentation as a connotation of inferiority. Mazrui emphasizes that " $[\mathrm{t}] \mathrm{he}$ primary differentiation between Arab and non-Arab was not skin colour, but language and culture. It was Europeans who raised the barrier of pigmentation higher in Africa" (Thought 285). The differentiation introduced by Europeans promoted the idea of subjugating Africans. Mazrui reiterates that

it took European conceptualization and cartography to turn Africa into a continent. To Europeans, 'black' was not merely descriptive; it was also judgmental. Arabs alerted the people of Sub-Saharan Africa that they were black. Europe tried to convince Black people that they were inferior. (Thought 278)

European occupation was disruptive both to the relations between people and the pre-existing fluid geographical interactions. The Europeans interrupted the preexisting relations and mobilities in order to advocate for their definition of African identity. Mazrui highlights that European imperialists "decided where one continent ended, and another began. For Africa, Europeans decided that our continent ended at the Red Sea rather than on the Persian/Arabian Gulf' (Thought 284). The colonial disruption then reshaped the relations Africans had amongst themselves because geographical boundaries marked spheres of influence apportioned to different European powers.

Territorial boundaries immensely diminished the primacy of Indigenous linguistic cultural modality as the defining aspect in the emergence of the 'African subject' since the geographic restrictions proffered stringent linguistic impositions. By so doing, Europeans designated the parameters of what it means to be African; a crucial aspect of African consciousness.

\section{Language and Ideology}

Ngugi wa Thiong'o identifies the linguistic detriment in the African continent as a result of the European conquest. He reminds us that, "The contention started a hundred years ago when in 1884 the capitalist powers of Europe sat in Berlin and carved an entire continent with a multiplicity of peoples, cultures, and languages into different colonies" (4). The underpinning statement presented by partition and scramble for Africa is the assumption that Africa was 'somehow' a 'clean slate'. Ngugi highlights the commensurate linguistic impact of European domination when he says, "Berlin in 1884 saw the division of Africa into the different languages of the European powers. African countries, as colonies and even today as neo-colonies, came to define themselves in terms of the languages of Europe" (5). Today we have linguistic categorizations of Africa like Francophone Africa, Portuguese-speaking Africa or Anglophone Africa. European linguistic modes dominate the formal cultural and economic regional infrastructure in the Sub-Saharan African states. The African national states are an invention of colonialism. National identities are outcomes of colonial territories. Colonies promoted a colonial agenda, and thus there is something problematic and irreversible about modern African statehood. That is why many African states have European languages as the national languages designated in the areas of education, trade and technology. Therefore, to eliminate the problem, we have to deracinate the basis of using colonial languages to fashion and propagate an African identity.

Ngugi substantiates that "The domination of a people's language by the languages of the colonizing nations was crucial to the domination of the mental universe of the colonized" (16). Linguistic colonialism thus inhibits the extent to which Indigenous Africans were enmeshed in their indigenous culture. The Eurocentrism acculturated the African colonial and postcolonial subjects using European linguistic modalities to promote the agenda of 'modernizing' Africa. Modernity (through colonialism and neo-colonialism) continues to have an abrasive impact on the true African identity. This abrasion leads to what Asante calls "the fragility of African Agency" (Liberating 646). We need to extricate African agency from the oppressive linguistic apparatus. Asante insists that, "[t]he key method is by distinguishing between the language of centeredness and the less precise language of decenteredness in relation to culture" (Liberating 648). Language from a socio-cultural perspective determines what (who) is at the center and what (who) is at the periphery. Ngugi remains unwavering on the issue of colonial decentralization through linguistic imposition. He corroborates that "[t]o control a people's culture is to control their tools of self-definition in relationship to others" (16). Colonialism in this regard promotes cultural disruption through the "the deliberate undervaluing of [the] people's culture, their art, dances, religions, history, geography, education, orature and literature, and the conscious elevation of the language of the colonizer" (16). We cannot establish an influential and instrumental bearing on African agency without interrogating the essence of language in the realization of African agency.

We have to begin by asking, from a linguistic perspective, how can we centre African agency? This question brings us closer to an understanding of the 
connection between language and agency within the African context. Ashcroft, Griffiths and Tiffin point out that in colonial discourse, agency "refers to the ability to initiate action in engaging or resisting imperial power" (10). The current linguistic phenomenon (multilingual nation states) depicts the tussle between the 'colonially purported African identity' and the 'actual African identity'. We then go on to ask: which languages are African, what makes them African and how do these languages foster an African sensibility? Ngugi mentions that the link between language and its culture is organic. Peremptorily, African culture can best exist and grow through its rightful conduit; an African language. Ngugi propounds that language contains "the collective memory bank of a people's experience in history. Culture is almost indistinguishable from the language that makes possible its genesis, growth, banking, articulation and its transmission" (15). An African language is thus the best 'aqueduct' for African agency. It both appraises the culture and ensures the transmission of knowledge. Asante invites us to challenge and thus dislodge cultural modalities that undermine African Agency. Hence, maintaining an Afrocentric lens ensures that "the manner in which the acquisition of knowledge is legitimized and then disseminated will affect an agency analysis that strips from oppressors the right to establish norms of human relations" (Liberating 650). Language is thus resourceful in debunking the colonial undertones contained in European languages in the transmission to the African context.

The reason we need to pose the question of African languages is identified by Ngugi in his examination of the impact of a colonial language. He poses the vital question of how a given language perpetuates individual reflection. He avers: "Since culture is a product of the history of a people which it in turn reflects, the child [in the colony] was now being exposed exclusively to a culture that was a product of a world external to himself. He was made to stand outside himself to look at himself" (17). The linguistic colonialism described by Ngugi reminds us that, when we do not clothe our cultures with our language, we inevitably displace ourselves. So, how can African languages bring us closer to ourselves as African agents? In his probe of centre and periphery on linguistic terms, wa Thiong'o proposes the need to dismantle the metaphysical empire that exists through the perpetuation of an image of Africa fashioned by Eurocentrism. Kiswahili thus offers a possibility to counter the dominant linguistic domination of European languages in the modern African identity. In 2019, Rwanda officially accepted Kiswahili as an official language thus expanding the use of the language in the East African region. Kiswahili is now spoken as an official language in Kenya, Uganda, Tanzania, Democratic Republic of Congo and Rwanda. Additionally, the language was also adopted as an official language by African Union (AU) East African Community
(EAC) and Southern African Development Community (SADC) thus raising its status as the most widely spoken African language. Within the context of globality Kiswahili has been acknowledged as a Pan-African medium thus functioning as a reliable linguistic modality in furthering an Afrocentric ethos. The big contest to consider now is the ways Kiswahili can help counter the metaphysical empire in liberating the African mind from a European definition and propagation of Africanness.

\section{The Case of Kiswahili in Fostering an Afrocentric Agenda: Kiswahili versus the Metaphysical Empire}

John Mugane states that the history of Kiswahili is embedded in a geo-political stretch called the Swahili coast. He accounts that "[i]t is impossible to say when the mixture that became a Swahili language began to form, but we know something about the setting in which the language developed" (17). Trade and contact with the outside world greatly influenced the later development and spread of the language. Mugane instantiates that

[t]he word for the language, Kiswahili, is derived from the Arabic sahil, meaning 'coast,' 'edge,' or 'border' - a place - and sawahil, meaning 'Swahili country.'

Swahili is thus the language of the prime Indian Ocean coastal strip stretching from Mogadishu in Somalia to Sofala in Mozambique and reaching out to all the adjoining islands (Pemba, Zanzibar, Lamu near the coast, and the Seychelles and Comoros farther offshore) as far as northern Madagascar - a distance of about 2,000 miles from the mainland. (17)

Heterogeneity is a defining factor of the language's origin. This foundational feature of bringing different cultures together poses the possibility to have a strong appeal (in the featured regions of Africa and beyond) in the aspiration for a broader Pan-African sensibility. Historically, Kiswahili culture presents itself as a welcoming culture. Mugane asserts that the language "has been the language of everybody [for instance] slaves from the nyika, the locally born, traders, porters, laborers, soldiers, and rulers, as well as diplomats, colonizers, and missionaries from far away" (20). And even as times changed and mobilities livened, "[b]y speaking Swahili, everyone who went to the East African littoral could choose to become Swahili, and many decided to do just that" (20). As a language that melds well with different cultures while nested in a culture (Swahili culture) that is welcoming and accommodating, it is a plausible channel to pursue an Afrocentric agenda. However, the attempt to centre African agency from a linguistic 
perspective ought to consider the influence of colonialism within the context of global coloniality.

Sabelo J. Ndlovu-Gatsheni notes that in the perspective of 'global coloniality' the metaphysical empire dominates. He claims that the metaphysical "is better understood in terms of how it worked on the minds of the colonized in the process adversely affecting the entire mental universe of the colonized through such technologies as epistemicides, linguicides, alienation, and cultural imperialism" (100). Ndlovu-Gatsheni thus raises a poignant philosophical question on how language among other cultural modalities promote colonialism. He notes that "The consequence has been the re-making of the African people in the image of the colonial conqueror. Metaphysical empire even invented new political identities such as "native"" (100). Achille Mbembe points out that the colonial empire in forging the various definitions such as 'a native' is primarily seeking "to establish [the] radical otherness of the colonized individual" (236). Colonial terminologies enforce the peripherality of the colonized. In these situations, when an entity or individual is defined, a commensurate meaning/placement/connotation is put in effect. It shapes how the defined entity or individual relates to and is perceived by the definer. This relationship then (re)iterates a relational hegemony. Therefore, we need to interrogate the language used to philosophize, describe, legitimate, identify and address the African experience.

Mazrui probes into the philosophical basis of language in the African context, propounding that "more important than the philosophy of language in Africa is the language of philosophy. Colonial and post-colonial ideologies are disproportionately in European languages" (Thought 17). The crux in Mazrui's proposition is the need to realize that "cultural philosophy is, in the first instance, conceived in indigenous languages [while] ideological philosophy in Black Africa is disproportionately in European languages" (Thought 16). Kiswahili offers a possibility to triumph over the problem of language in the formation and propagation of the African thought. Mazrui gives an example of Julius Nyerere, explaining that

Julius Nyerere is the most enterprising of African philosophers. He has philosophized extensively in both English and Kiswahili. He has tried to tear down the language barrier between ancestral cultural philosophy and the new ideological tendency of the post-colonial era. (Thought 22)

Mazrui contextualizes that in African societies, the relationship between European languages and African languages should entail the languages speaking to each other as equals. It should be a co-cultural transaction. Within the context of globalization, it is hard to avoid cross-cultural transactions. However, there should be fair terms upon which the various 'conduits' (such as language) of transaction are founded.

Kiswahili remains embedded in Eastern, Central and Southern Africa due to the basis of its origin along the region regarded as the Swahili Coast. The spread into the inland is rapid but still encounters challenges. Alamin Mazrui and Ali Mazrui probe into the relevance and reaches of Kiswahili language in Eastern and Central Africa. They mention that within an international context, Kiswahili is limited by popularity and not the embeddedness within the people of Eastern, Central and Southern Africa. They postulate that:

Much of the recent debate as to whether it is wise to make Kiswahili the official language of a country like Kenya or Uganda has rightly pointed out that Kiswahili is less of an international language than English. What has been overlooked is the simple fact that when all is said and done, Kiswahili is still the most international of all the indigenous languages of the African continent or of the Black people as a whole. Should Kiswahili be underestimated because it is less international than English? Or does it deserve to be developed further because it is the most internationally promising of all the native-born languages of Africa? (Swahili 100)

The formal refutation on the status of Kiswahili has always been a question of 'modernization'. Academics and policymakers grapple with the reaches of the language within a global spectrum. Alamin and Ali foreground that "Kiswahili is still the most international of all the indigenous languages of the African continent" (Swahili 100), exposing that the determiner of Kiswahili's globality is not the Afrocentric (net)workings but rather the reference to the West. Ali and Alamin illuminate that the disadvantage Kiswahili faces comes from the fact that "In reality, African countries have been aiming at two related processes, one that has sometimes been called 'modernization' and the other 'development"' (Swahili 105). The two phenomena pit Africa with the West since "'Modernization' has been seen as a process of change in the direction of narrowing the technical, scientific, and normative 'gap' between industrialized western countries and the Third World. Partly because the industrial revolution first took place in the West, Western civilization as a whole became the criteria for assessing and measuring "modernity"' (Swahili 105). Alamin and Ali thus expound that if the point of reference is the West, then it means that "Kiswahili cannot be examined in isolation but has to be related to the impact of its European rivals" (Swahili 107). In other words, juxtaposing the position and essence of Kiswahili with English or French constraints the relevance of the language. This mentality 
reduces the language merely to a rival rather than attributing it with the propagation of African agency.

Kiswahili has the potential to be the language of trade, education and technology. It can accommodate and further an Afrocentric sensibility because of its indigeneity in Africa, where it has spread and established strong links among the Eastern, Central and Southern African communities. Historical evidence dates the use of the language along the East African coast around the tenth century. Kiswahili has had a long history in East and Central Africa. The existence of the language subsumes the historical and cultural experiences that have defined the region. For instance, during the colonial period, it was a language of resistance. Alamin and Ali historicize that "three wars were particularly important in the history of Kiswahili in East Africa. One war was the Maji Maji Resistance in German Tanganyika, which broke out in 1905. The second important war for the evolution of Kiswahili was World War I, and the third was World War II" (Swahili 36). From a historical point of view in East and Central Africa, Kiswahili has promoted "inter-ethnic African unity" (Swahili 39) against colonial powers. It is unifying. Kiswahili fosters an Afrocentric consciousness and, on this accord, Alamin and Ali encourage that "Africans therefore must continue to strive to set their own terms of definition and discourse on the global arena" (Swahili 161).

On the science and technological front, Ali and Alamin assert that "[n]o language is inherently incapable of handling modern science and technology" (Swahili 25). They instantiate that Professor Mohammed Hyder, who was a Zoology lecturer at the University College in Nairobi, was able to write a scientific paper in Swahili "on the subject of 'The Effect of Thyroid Stimulating Hormone on the RadioActive Iodine Uptake in Beef Thyroid Tissue In Vitro", (Swahili 25). Ali and Alamin use this example to illustrate that Kiswahili can function in scientific discourse. They quote Hyder, who postulates that

[t]here is no good reason why this development of a 'technical limb' of Swahili through the Swahilization of [technical] terms should weigh heavily on our consciences. Examination of any technical or scientific journal in English, French, German, Russian, or Chinese shows clearly that such technical terms are really international in usage. (Swahili 25)

The point emphasized is that Kiswahili or any other language has the potential to transmit scientific language because it has the potential. Alamin and Ali insist that "Kiswahili has demonstrated a remarkable capacity to adopt linguistic items from other languages $[\ldots]$ in the process of nominalizing potential. In short, Kiswahili has been flexible enough to respond creatively to new linguistic challenge of the scientific age" (Swahili 27). Consequently, the arguments presented above remind us that with investment to align Kiswahili with vital contemporary discourses like science and technology, Kiswahili scholarship enables the language to fit within the broader regional and international platforms.

Kimani Njogu encourages that "Kiswahili can be foregrounded as the language of social and economic activity and [thus] contribute in inter-ethnic understanding" (21). It is integrative and thus centers an African sensibility. Kiswahili may not be indigenous to many Eastern, Central and Southern African communities, but it has the potential to foster cultural, economic and political growth. Mugane points out that Kiswahili's contact with Bantu language groups manifests in the fact that "[m] any Swahili words have cognates in Proto-Bantu, the hypothesized language of the original groups who left what is now southeastern Nigeria some five thousand years ago" (45). This phenomenon depicts that Kiswahili has a long history with the Bantu language group which predominantly occupies Eastern, Central and Southern Africa. Thus, it maintains a favourable multilingual environment. In the broader scheme of things,

Njogu instantiates that

the African Union passed a resolution making Kiswahili one of the organic official languages in July 2002 and it was implemented at the General Assembly in Addis Ababa in July 2004. The working languages of the African Union are now Arabic, English, French, Kiswahili, Portuguese and Spanish and a few other African languages. (24)

John M. Mugane emphasizes that "The African Union (AU)" seen as a key unifying fabric of African states "nurtured the same sentiment of continental unity in July 2004" (3) when they made the decision to adopt the language. He reminds us that "[t]oday, Swahili is the African language most widely recognized outside the continent. The global presence of Swahili in radio broadcasting and on the Internet has no equal among sub-Saharan African languages" (6). Mugane identifies that up to date "Swahili is broadcast regularly in Burundi, the Democratic Republic of the Congo (DRC), Kenya, Liberia, Nigeria, Rwanda, South Africa, Sudan, Swaziland, and Tanzania" (7). The expanding scope of the language continues to show the potential of the language in crafting a broader African identity. Mugane substantiates that "Africa's Swahili-speaking zone now extends across a full third of the continent from south to north and touches on the opposite coast, encompassing the heart of Africa" (1).

Njogu and Mugane pose a more significant question insisting that Kiswahili not only offers a possibility to foster 
an Afrocentric sensibility but also presents a solution over the ethnic tension brought by divisive vernacularism. In the Kenyan context, Pius Kakai Wanyonyi posits that ethnic consciousness was a doing of colonialism. He reminds us that the territorial boundaries were introduced by colonial masters as a divisive strategy. The colonial strategy

weakened the pre-colonial intermingling [thus] helped to intensify and fossilize ethnic consciousness amongst different communities and ended up promoting the feeling of exclusiveness and eventually planted the seeds of ethnocentrism and the urge for ethnocracy.

Kiswahili has actively countered this material sociological dysfunction in its role as a regional and national language. Alamin and Ali regard the role of Kiswahili in the face of negative ethnicity as "detribalization" urging that "Kiswahili is also linked to the of process of urbanization. Kiswahili has been a facilitating factor behind such urbanization and has served as a lingua franca among the different ethnic communities" (Swahili 3). Kiswahili fosters a more integrated society. Due its closer indigeneity to the East African community, it centres an Afrocentric ethos by posing a positive evolution of the African linguistic situation. Ali and Alamin persist on the embeddedness of Kiswahili in Africa specifying that

Kiswahili and its achievements [is] presented as the product of the collective genius of the African people themselves who, at the maximum, just borrowed items from Arabic - as English borrowed from French, for example - to meet certain functional needs. (Babel 161)

We also ought to consider the legality aspect of languages in Africa. Justice is a crucial tenet in the advancement of society. Ali and Alamin point out that

Anglophone Africa has inherited from the colonial experience, many litigants who are bound to the oralindigenous linguistic tradition are precluded from making any real contribution to the (re)construction of the legal process. (Babel 121)

The legality of language is a postcolonial reality built on the decentralization of Africanity. They go on to caution that

Africa's legal ideology continues to be overwhelmingly Eurocentric partially because linguistically, it continues to marginalize the less Europeanized members of society, and those who are best placed to contribute towards its Africanization. (Babel 121)

Recent developments in Kenya require the use of Kiswahili in some parliamentary proceedings. The insertion of Kiswahili on a parliamentary level is a stride towards the use of Kiswahili in law. In Kenya and Tanzania, experts have drafted the constitutions in Kiswahili. The use of Kiswahili in these national levels promises a lot on the future of the language.

In East and Central Africa, literacy continues to be the leading avenue for the spread of Kiswahili. Since the Nairobi revolution of 1968, literacy has promoted an Afrocentric conscious in a strife Apollo Obonyo Amoko regards as a strive to "promote appropriate forms of citizenship" (6). Kiswahili scholars like Said A. Mohammed, Ken Walibora, Julius Nyerere and Wallah bin Wallah among many others have immensely contributed to the literary imagination of East African society through Kiswahili. Most of their writings have pushed the discussion forward in primary, secondary and tertiary education. The Kiswahili dictionary kamusi has seen constant updates in alignment with technology, science, law and cultural advancement. For instance; a word like 'computer' has undergone Swahilization into 'kompyuta', another example is 'television' which became 'televisheni' and also 'email' became 'baruapepe'. Kiswahili's adaptive nature can be seen in a word like 'baruapepe': 'barua' means 'letter' in Kiswahili and 'pepe' is a Kiswahili adverb which denotes 'happening in an unconventional manner'. Kiswahili can be more than we think. Its adaptability and transnational reaches paint a clear picture of its importance. Given that the pace of the world on the technological, economic and cultural front is not slowing down, we then should consider adopting a more reliable socio-cultural approach that guarantees that we remain key participants in our reality as well as appearing as key in situations that are cross-cultural and cross-national within a global reality.

\section{Moving Beyond the Nation}

Patrick Chabal points out that we should start thinking of "supra-national solutions" in light of how "recent and artificial African nation-states are" (40). In contemplating about the future of Africa we ought to "set in train new forms of association which would in time make the present national divisions of Africa redundant" (40). Kiswahili has already started showing the potentiality of creating a broader identity. Ali and Alamin conceptualize this as the transnational Swahili state. A socio-cultural identity that appreciates the centrality of African agency in discussions about and for Africa. This ought to be the future. Chabal cautions us that "there are more voices expressing both the limitations of the existing system of nation-states and the need for new forms of co-operation" (40). Chabal problematizes the legitimacy of the nation-state in Africa in light of "the present economic crisis and the apparent nonviability of a number of smaller or resource-less African countries have led many to [...] propose radical supra- 
national solutions" (41). Chabal is advocating for a more pan-African aspiration which aligns with the transnational Kiswahili identity Ali and Alamin identify.

It is however clear that the Afrocentric basis of the language proffers the propitiation of interruptions of colonialism through an integrative agenda. Kiswahili has furthered the conversation on the future of Africa. The relevance of Kiswahili within the context of decolonization and Afrocentrism encourages the conception of a bright future for the continent. Ali and Alamin point out that to cater for a more progressive ethos in deliberations about the future of Africa, we have to think of decolonization. They instantiate that from a linguistic perspective, decolonization involves "indigenization, domestication, diversification, horizontal interpenetration, and vertical counter-penetration" (Swahili 128). Through indigenization Ali and Alamin emphasize that this particular process entails "the utilization of indigenous resources, ranging from native personnel to aspects of traditional local technology" (Swahili 128).

Specifically, this particular aspect ensures preservation rather than discarding the essential undertones of indigeneity.

Kiswahili as we have seen maintains a healthy relationship with the indigenous cultures. The kind of Kiswahili spoken depends on the region. There is Kiswahili with regional inflections. This particular attribute aligns with what Ali and Alamin regard as domestication. They assert that domestication "involves making imported resources more relevant to the local society. [Thus] To domesticate is to make [something] respond to local imagery, figures of speech, sound patterns, and to the general cultural milieu of the region" (Swahili 129). As we have seen, the capability of Kiswahili to adapt scientific vocabulary to a Kiswahili perspective marks the capability to domesticate things into a Kiswahili perspective.

Ali and Alamin use the term diversification to connote to "the ways of perception, sources of expertise, techniques of analysis, types of goods produced, markets for the products, general trading partners, aid-donors, and other benefactors" (Swahili 130). They outline these factors in order to heighten the importance of Kiswahili language in the interactions that raise the economic, social and political stakes in Africa. Language is essential on the level of establishing the infrastructural basis of the interactions that are bound to occur. The choice to put Kiswahili in this conversation then means that we don't allow the socioeconomic realities regulate the terms. If we grow the reaches of the language, it means that we go into these interactions with the intend to have a co-cultural interaction. If we don't pay attention to the linguistic aspect, it means that we will still feel like we need European languages to interact among ourselves.
On the point of horizontal inter-personal-penetration, Ali and Alamin emphasize on the need to promote "a greater exchange among, say, African countries themselves" (130) in a quest to build a cohesiveness among African nations. Kiswahili can be a conduit in which this network is built for the purpose of eliminating the economic dependency of African nations on the West. Such a relationship will ensure we foster an Afrocentric ethos and thus move forward. It encourages an aspiration for a pan-African sensibility and thus presents a possibility to forge a unified front in light of global transactions.

\section{Conclusion}

We have to pose questions on the future of Afrocentrism within the African setting. We can begin with the potential Kiswahili offers the integration of Eastern, Central and Southern Africa. In all areas of the African reality, traces of Eurocentrism persist, thus posing a threat to the attainment of African agency. Homi Bhabha reminds us that through "the process of reinscription and negotiation $[\ldots]$ emerges the process of agency both as a historical development and as the narrative agency of historical discourse" (191). From a postcolonial linguistic perspective, it is thus vital to engage with the question of an African language in the process of 're-inscribing' African identity. Such an intervention will facilitate an incisive evaluation of the socio-cultural realities that are key to the African experience. Asante reminds us the Afrocentric

objective has always been to create space for conscious human beings who are, by virtue of their centeredness, committed to sanity. This is the key to re-orientation and re-centering so that the person acts as an agent rather than as a victim or dependant. (Manifesto 34)

Kiswahili, as a powerful linguistic modality, offers the possibility of promoting African agency culturally, politically and economically. Its mainstay is the promotion of a wider network of alliance (among African communities) and allegiance (to a broader Afrocentric ethos). Kiswahili's socio-cultural basis is embedded in the proliferation of an African ethos due to its adaptability to other ethnic languages and also the capability to represent an African sensibility within an international level. The growing entrenchment of the language can help us combat the epistemological and systemic problem of recolonization of the continent. The strong philosophical and cultural roots Kiswahili possess promise that as an Afrocentric language, Kiswahili can help liberate and centre African agency.

\section{References}

Chabal, Patrick. "The African crisis: context and interpretation." Postcolonial Identities in Africa. Edited by Werbner, Richard 
P., and T. O. Ranger. Zed Books, Atlantic Highlands, N.J., 1996.

Wanyonyi, K. Pius. "Historicizing Negative Ethnicity in Kenya." (Re)Membering Kenya. Edited by Gona, G. M., Wa Mungai, Mbugua. Twaweza Communications, Nairobi, 2010.

Amoko, Apollo Obonyo. Postcolonialism In the Wake of the Nairobi Revolution: Ngugi Wa Thiong'o and the Idea of African Literature. Palgrave Macmillan, 2010.

Asante, Molefi K. An Afrocentric Manifesto: Toward an African Renaissance. Polity, Cambridge, 2007.

Asante, Molefi Kete. "Afrocentricity: Notes on a Disciplinary Position." Handbook of Black Studies.Thousand Oaks: SAGE Publications, Inc., 2006. 152-164.

http://sk.sagepub.com.login.ezproxy.library.ualberta.calreferen ce/hdbk_blackstudies/n11.xml

Asante, Molefi Kete. "A Discourse on Black Studies: Liberating the Study of African People in the Western Academy." Journal of Black Studies, vol. 36, no. 5, 2006, pp. 646-662. JSTOR, www.jstor.org/stable/40026678.

Ashcroft, Bill, Gareth Griffiths, and Helen Tiffin. Postcolonial Studies: The Key Concepts. Routledge,

2013, https://ebookcentral.proquest.com/lib/concordiaabebooks/ detail.action?docID $=1244807$

Bhabha, Homi K. The Location of Culture. Routledge, 1994.

Brown, William, and Sophie Harman. African Agency in International Politics. vol. 2, Routledge,

2013, https://ebookcentral.proquest.com/lib/concordiaabebooks/detail.action?docID $=1157754$

Gona, G. M., et al. (Re)Membering Kenya. Twaweza

Communications, Nairobi,

2010, http://search.ebscohost.com/login.aspx?direct=true\&scop $\mathrm{e}=\mathrm{site} \& \mathrm{db}=\mathrm{e} 000 \mathrm{xna} \& \mathrm{AN}=411027$

Gurr, Andrew, and Pio Zirimu. Black Aesthetics: Papers from a Colloquium Held at the University of Nairobi, June, 1971. East African Literature Bureau, Nairobi, 1973.

Mazrui, Ali A. African Thought in Comparative Perspective. Cambridge Scholars Publishing, Newcastle Upon Tyne, 2014, https://search.ebscohost.com/login.aspx?direct=true\&sco $\mathrm{pe}=\mathrm{site} \& \mathrm{db}=\mathrm{e} 000 \times \mathrm{xna} \& \mathrm{AN}=748503$

Mazrui, Ali A., and Alamin Mazrui. Swahili State and Society: The Political Economy of an African Language. East African Educational Publishers, Nairobi, 1995.

Mazrui, Ali A., and Alamin Mazrui. The Power of Babel: Language \& Governance in the African Experience. J. Currey; Chicago, Oxford, England, 1998.

Mbembe, Achille. On the Postcolony. vol. 41, University of California Press, Berkeley, USA, 2001.

Mudimbe, V. Y. The Invention of Africa: Gnosis, Philosophy, and the Order of Knowledge. Indiana University Press, Bloomington, 1988, http://hdl.handle.net/2027/heb.02645.0001.001 http://hdl. handle.net/2027/heb.02645.0001.001

Mugane, John M. The Story of Swahili. Ohio University Press, Athens, Ohio, 2015.

Ndlovu-Gatsheni, Sabelo J. "Metaphysical Empire, Linguicides and Cultural Imperialism.” English Academy Review. Vol 35, no. 2, 2018, pp. 96-115, https://doi.org/10.1080/10131752.2018.1530178.
Wa Thiong'o, Ngũgĩ. Decolonising the Mind: The Politics of Language in African Literature. J. Currey; Portsmouth, N.H., Woodbridge, Suffolk, UK, 1986.

Njogu, Kimani, and Seifudein Adem. Critical Perspectives on Culture and Globalisation: The Intellectual Legacy of Ali Mazrui. Twaweza Communications Ltd., Nairobi, Kenya, 2017.

Reviere, Ruth. "Toward an Afrocentric Research Methodology." Journal of Black Studies, vol. 31, no. 6, 2001, pp. 709-728. JSTOR, www.jstor.org/stable/2668042

Spivak, Gayatri C. A Critique of Postcolonial Reason: Toward a History of the Vanishing Present. Harvard University Press, Cambridge, Mass., 1999.

Werbner, Richard P., and T. O. Ranger. Postcolonial Identities in Africa. Zed Books, Atlantic Highlands, N.J., 1996. 